\title{
Setting up the water balance simulation model WaSiM for the assessment of climate change impacts in Chiba basin, Tunisia
}

\author{
Franz Hummel, Joachim Post, Günter Strunz \\ Department of Civil Crisis Information \& GeoRisks \\ German Aerospace Center, DLR \\ Oberpfaffenhofen, Germany \\ Franz.hummel@dlr.de
}

\author{
Ralf Ludwig, Annemarie Hoffmann \\ Department of Geography \\ Ludwig-Maximilians-University, LMU \\ Munich, Germany
}

\author{
Sihem Benabdallah \\ Laboratory of Geo-Resources \\ Centre de Recherches et des Technologies des Eaux CERTE \\ Borj-Cedria, Tunisia
}

\begin{abstract}
The project CLIMB (Climate Induced Changes on the Hydrology of Mediterranean Basins - Reducing Uncertainty and Quantifying Risk through an Integrated Monitoring and Modeling System, www.climb-fp7.eu) investigates the impacts of climate change on hydrological quantities and the occurrence of extreme events for the Mediterranean Region and neighboring countries. This study gives insights into setting up the "Water balance Simulation Model" WaSiM in Chiba basin, situated in the north-east of Tunisia. Besides that, the intended climate change impact assessment framework for this region is presented which also includes uncertainty information within the climate and hydrological modeling chain. Finally, some preliminary results are presented which indicate a considerable decline of total available water and associated risks in the study area between the reference (1971-2000) and scenario period (20412070).
\end{abstract}

Keywords-Hydrological modeling; climate change; uncertainty analysis; risk assessment; water resource management; WaSiM; CLIMB Project

\section{INTRODUCTION}

The Mediterranean region is very vulnerable to possible climate induced changes on the hydrological budgets and extreme events. Those changes are expected to have strong impacts on the management of water resources and on key strategic sectors of regional economies [1]. Nowadays, more and more hydrological impact models are used to assess impacts of future climate change. However, existing monitoring and modeling tools in the Mediterranean region are scarce and often only feature insufficient data quality required for hydrological impact modeling. Within the project CLIMB (Climate Induced Changes on the Hydrology of Mediterranean Basins - Reducing Uncertainty and Quantifying Risk through an Integrated Monitoring and Modeling System, www.climb- fp7.eu) one main goal is to develop a state-of-the-art monitoring and modeling framework in order to facilitate a comprehensive climate impact assessment for a total of seven Mediterranean test sites, namely the Thau catchment in France, Rio Mannu di San Sperate in Sardinia, Chiba basin in Tunisia, Noce in Italy, Izmit Bay, Kocaeli, in Turkey, Nile Delta in Egypt as well as Gaza Aquifer in the Palestinian administered areas of Gaza strip. This study gives an insight into setting up the "Water balance Simulation Model" WaSiM for the Chiba basin in the north-east of Tunisia. The WaSiM model is part of a multi-model climate change impact assessment strategy which will derive new findings for this region within the CLIMB Project.

\section{STUDY SITE DESCRIPTION}

The basin of Wadi Chiba covers an area of the order of $200 \mathrm{~km}^{2}$ and is located in the administrative limits of the Nabeul Governorate, commonly known as the Cap Bon region, Northeast of Tunisia. It falls within the following coordinates: $36^{\circ} 20^{\prime} \mathrm{N}$ to $37^{\circ} 10^{\prime} \mathrm{N}$ and $10^{\circ} 30^{\prime} \mathrm{E}$ to $10^{\circ} 10^{\prime} \mathrm{E}$. The catchment is limited to the West by Djebel Sidi Abderrahmane, the North and North-East by the watershed of the Oued Bou Dokhane and to the Southwest by the watershed of the Oued Korba (Fig. $1)$.

Even though the governorate of Nabeul represents 1,72\% of the total country area and it is considered among the most populated regions in Tunisia with an urbanization rate of $66.1 \%$, its agricultural production contributes with $15 \%$ to the national agricultural production.

The climate is under the influence of the Mediterranean Sea with a mean annual rainfall of $450 \mathrm{~mm}$. It can be as low as $246 \mathrm{~mm}$ (2008) and as high as $1043 \mathrm{~mm}$ (2003). Over the year, the rainy season extends from September to March with peaks 
for the months of September, December and January. The mean annual temperature is $19^{\circ} \mathrm{C}$.

Most parts of the catchment are devoted to agriculture uses with the exception of some degraded forests and dense bushes on hilly areas. Major crops grown in the catchment are cereals representing $48 \%$ of the total area, tree cultivation (olives and citrus) with $22 \%$, and winter and summer vegetables with $9.3 \%$.

In the Chiba basin, the agricultural water presents a fundamental issue to agriculture-based rural livelihoods and its sufficient availability is considered as a constraint to agriculture production. In fact, as early as 1963, a dam was constructed on the Chiba Wadi to safeguard the irrigation of agricultural land.

Furthermore, in the 1990's, the ministry of agriculture instituted a financial scheme to help all farmers installing drip irrigation systems in order to save water. In addition to that, an artificial recharge site was installed in 2008 using treated waste water in the lower part of the basin to make a barrier for sea water intrusion.

With the consensus that climate changes will induce reductions in runoff within the Mediterranean region, it becomes of great importance to quantify the impacts of climate change and the related uncertainties on the water availability within the Chiba basin and to determine potential agriculture water management issues that consequently need to be raised [2].

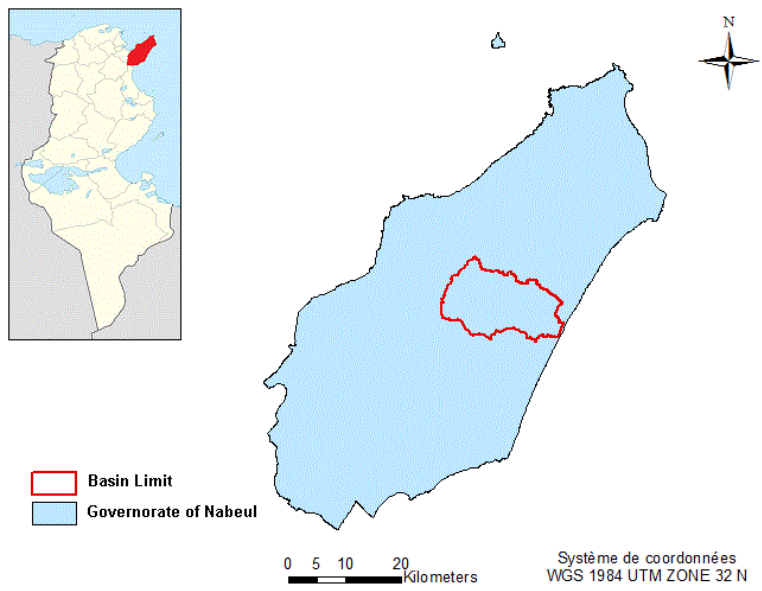

Figure 1: Case Study location.

\section{OVERVIEW OVER THE WASIM MODEL}

The "Water balance Simulation Model" (WaSiM) is a gridbased, modular water flow and balance simulation model, which has been developed by Jörg Schulla at the Swiss Federal Institute of Technology (ETH) in Zurich. It is used for hydrological issues like impact analyses for river basins, runoff forecast or the modeling of substance transport [3].
In the earliest development phase WaSiM comprised of a soil module based on the TOPMODEL approach [4], but the model has been extended several times since its initialization (1994 - 1996). A considerable innovation introduced a more physical based soil module to the model, using the RICHARDS equation [5]. WaSiM is able to simulate the water circuit on a small-scale as well as for large catchments with several thousands of square kilometers. The temporal resolution may range from minutes to days. WASIM can therefore be used in different spatial and temporal scales, and is mainly based on physical approaches. The minimum data requirements of the model are time series of temperature and precipitation as well as raster data sets for topography, soil types and land use classes [6]. The structure of the WaSiM model is shown in Fig. 2.

Depending on data availability and the purpose of the study, the combination of active sub-models can be chosen individually and most sub-models are designed to process with different mathematical complexity. For instance, there are different ways to perform the spatial interpolation of meteorological data and also the evapotranspiration module incorporates a number of different calculation methods, namely techniques according to Haude, Hamon, Wendling or PenmanMonteith. All parameter settings and module configurations are summarized in one control file. Finally, there are two kinds of model outputs. Spatially distributed model outputs show information on a map in a resolution depending on the pixel size of the chosen model resolution. Statistical data sets give information on the catchment scale or also on sub-catchment scales, if those have been defined by the user before the model processing [6].

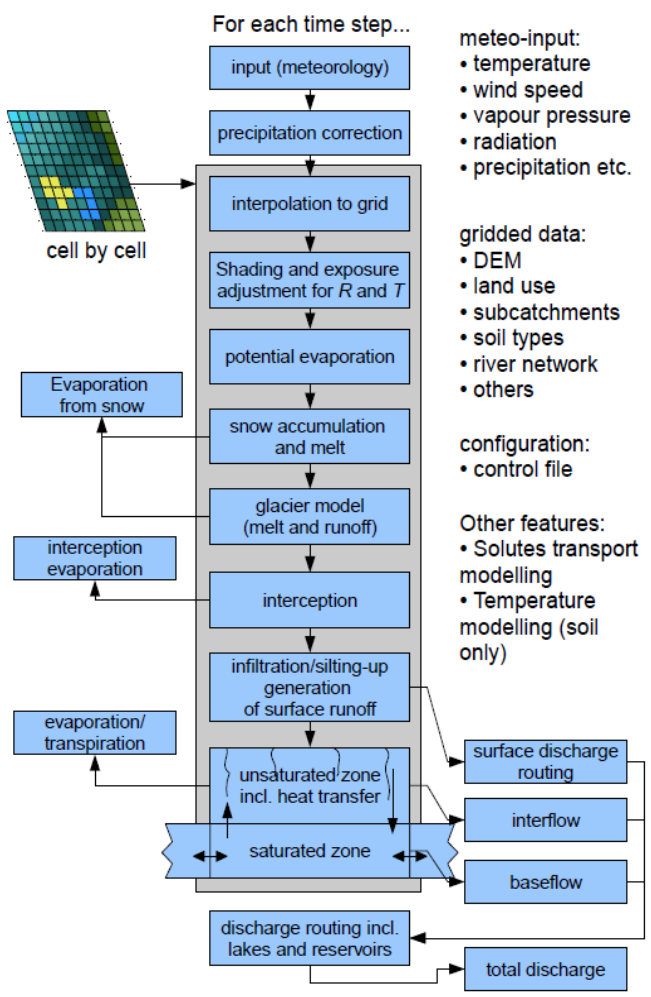

Figure 2: Model Structure of the WaSiM model [1]. 


\section{METHODOLOGY}

Three main steps have been performed in order to set up the water balance simulation model WaSiM for the Chiba basin, Tunisia:

- $\quad$ Gathering and processing of officially provided input data

Transferring the information from the officially provided input data into a first plausible parameterization concept for the model

- Performing calibration/validation work in order to guarantee the quality and capability of the WaSiM model to reproduce observed characteristics with at least two independent criteria. In this case, a comparison of modeled and observed discharge as well as a comparison of evapotranspiration patterns from the model and patterns derived from remote sensing imagery

The first step consisted of gathering and processing of officially provided input data which would be needed in order to run the WaSiM model. There has been an intensive exchange between the case study leader and all modeling partners active in Chiba basin to guarantee a basic set of input data sets which could serve all models applied in the catchment as a basis to perform the modeling work for the CLIMB Project. Other models applied in this region are the Soil Water Assessment Tool SWAT [7] and the CATchment HYdrology model CATHY [8]; maybe also the model MIKE-SHE [9, 10]. Officially the following input data sets were provided for all models:

- Digital elevation model (raster-files in $50 \mathrm{~m}, 150 \mathrm{~m}$ and $250 \mathrm{~m}$ spatial resolution)

- $\quad$ Soil map (shape-file, 10 classes)

- $\quad$ Land use map (shape-file, 12 classes)

- Catchment boundaries (raster-files in $50 \mathrm{~m}$ and $250 \mathrm{~m}$ spatial resolution)

- Sub-catchment boundaries (shape-files for 3 subregions as well as 9 sub-regions)

- Information on cropping patterns

- Information regarding the Chiba dam reservoir in the center of the basin (volumes, discharge rates)

- Information regarding the Korba aquifer in the east of the basin (depth to bedrock spatially distributed as well as point information on depth to groundwater level)

The Digital Elevation Model (DEM) was generated with a scale of 1:50 000 using contours lines, created for the purpose of this study, from National Topographic Maps. The soil and the land use layers were produced by the Soil and Water Conservation Agency from soil maps at a scale of 1:50 000 and from Landsat Thematic Mapper images for the year 2000. Soil properties were extracted from several technical studies realized by the National Ministry of Agriculture [2].
The WaSiM model is set up to simulate water flow with the RICHARDS equation. Evapotranspiration is calculated according to the Penman-Monteith equation. Beyond that, groundwater dynamics of the Korba aquifer are considered. There is little information on irrigation as well as Chiba dam reservoir management. Therefore those aspects are omitted in the model. Regardless, the Chiba dam reservoir is implemented in the model as a dynamic water surface which can run dry and refill during the simulated time period. Officially provided input data sets were processed to approximate spatially distributed aquifer thickness information needed for the WaSiM model. For that effort, the point information on depth to groundwater level was interpolated and combined with the spatially distributed data set of depth to bedrock.

The second step was to transfer the information from the officially provided input data into a plausible parameterization concept for the model. For these efforts also a lot of harmonization has been done between all modeling groups and the case study leader. This procedure guarantees that all models applied in one catchment use the officially provided input data for that region in the same plausible way. The need for such efforts arose during the conceptualization of the comprehensive uncertainty assessment strategy. For example, a certain soil class should not be treated like sand with a small soil thickness in one model while another model treats the same class more like clay with a high soil thickness. This would have considerable impacts on the water balance of this class between individual models which could not be attributed to different model structures. Other aspects for harmonization may relate to (but is not limited to) any component within the parameterization concepts of soil or land use classes as well as (if present and addressed) groundwater properties, irrigation schemes in agriculture, management of reservoirs or glacier dynamics. Therefore, a blueprint of a model harmonization strategy was developed in collaboration with all modeling partners active in Chiba basin. Within that, also guidelines are given on how to derive a plausible parameterization for important components in order to transfer the officially provided input data into the modeling environment. For example, official parameterization concepts for soil and land use classes of WaSiM were taken from the SWAT database. Nevertheless, not all parameter settings of the SWAT database are meaningful for other models, so the most plausible parameterization of $\mathrm{WaSiM}$ has to be determined within the calibration/validation efforts.

Within the model harmonization also a calibration/validation strategy was developed which aims to ensure the quality and capability to reproduce observed characteristics with the final configuration of each individual hydrological impact model with at least two independent criteria (Step 3 for the model setup). For the WaSiM model two criteria will be investigated, namely a comparison between observed and simulated discharge as well as a comparison between simulated evapotranspiration patterns from the model and patterns derived from remote sensing imagery. The calibration/validation efforts are on-going. Results of this work will be presented in future publications. Regardless, the models will not be over-calibrated in order to achieve best possible congruence with (scarce) observed data. The aim is more to set 
up the models in the most robust and plausible way and use available data as coarse information to assess overall goodness of the simulation.

The officially provided input data sets, the model harmonization as well as the calibration/validation strategy ensure that all models in a given case study site are set up in a most similar, robust and plausible way, while maintaining model specific characteristics. Differences in model results between the hydrological impact models in a given case study site can then be more convincingly attributed to effects of different model structures. This is important for the Model Structure Uncertainty Study MUS which is part of LEVEL 1 uncertainty analysis efforts which will be performed in all test sites.

An integrated modeling setup was established in order to investigate climate change impacts on water resources and associated risks. This was done in order to investigate (1) the effects of using several climate data sets on a robust model configuration named Climate Signal Uncertainty Study (CUS), (2) the effect of performing CUS with several hydrological impact models in each case study site named Model Structure Uncertainty Study (MUS) and (3) parameter related uncertainty in the modeling chain constituting the Parameter Uncertainty Study (PUS). CUS and MUS together build a basic level of uncertainty analysis for all seven case study sites within the CLIMB Project, subsequently also denoted as the LEVEL 1 approach. LEVEL 1 builds on four climate models which have been determined within a screening process achieving the best results in representing long-term climate characteristics (monthly averages, monthly fluctuations and extremes) in all case study sites. Thereby, each climate model features climate data sets in not bias-corrected, bias-corrected and downscaled/disaggregated format. Altogether 24 model runs for CUS have been set up based on the selection of one emission scenario, four combinations of global and regional climate models as well as two time periods $(1971-2000$ and 2041 - 2070) leading to eight runs based on not bias-corrected climate data sets, eight runs for bias-corrected climate data sets and eight runs for downscaling or disaggregation of bias corrected data. In contrast to CUS and MUS, PUS will be performed in selected sites only, but also in the Chiba basin in Tunisia. PUS is an extension of LEVEL 1 and hence also denoted as LEVEL 2 within the comprehensive uncertainty assessment strategy of CLIMB. Each simulation setup within a hydrological impact model covers 30 years. This results in a variety of model outcomes for each time period. Hence, information on a specific characteristic (e.g. relative soil water content in the root zone) for a given day consists of 30 values within a single model run. The following remarks give an insight into preliminary results of CUS and PUS. The next chapter gives an insight into some preliminary results.

\section{PRELIMINARY RESULTS}

All model runs of PUS indicate a decrease of relative soil water content in the root zone for every season of the year. Winter (DJF), spring (MAM) and summer (JJA) feature statistical significance. Thereby all individual months show a decline except November (statistical significance for January to September). Changing characteristics of soils, plants and Korba groundwater aquifer lead to a distinct spread of soil water contents within PUS. This is pronounced during the wet season (September to April), when water availability varies considerably due to the high variability of rainfall in the semiarid climate of Chiba basin. The ratio between the highest and lowest inter-annual precipitation sums is 4.4 [11]. Uncertainties are higher in times of varying rainfall. This expresses in a much wider band of projected values for individual months. During summertime, all simulations project a small band of very low values. Therefore a higher confidence exists that water will be scarce during that time of the year (Fig. 3). Best estimates project annual mean soil water contents in the root zone of 9.3[Vol.-\%] +/- 1.9[Vol.-\%] and 8[Vol.-\%] +/$1.5[\mathrm{Vol} .-\%]$ for the reference and scenario period respectively which results in a decline of 1.3[Vol.-\%] +/- 0.25[Vol.-\%] $(-14 \%+/-2.7 \%)$ between $1971-2000$ and $2041-2070$. This trend can mainly be attributed to a reduction of annual precipitation sums by $59.3 \mathrm{~mm}+/-17.2 \mathrm{~mm}(-16.9 \%+/-4.9 \%)$ from $351.3 \mathrm{~mm}+/-105.4 \mathrm{~mm}(1971$ - 2000) to $292 \mathrm{~mm}+/-$ $81.8 \mathrm{~mm}(2041-2070)$. Chiba basin was modeled with an area of $176 \mathrm{~km}^{2}$ in this case. Therefore a decline of $59.3 \mathrm{~mm}+/-$ $17.2 \mathrm{~mm}$ adds up to a water quantity of 10.4 million cubic meters $(\mathrm{Mm} 3)+/-3 \mathrm{Mm}^{3}$ of less water on average in each year. Inter-annual variability may even lead to a more pronounced decline in individual years. These facts indicate that precipitation constitutes the key input factor within this study. High variability of rainfall results in a high degree of uncertainty for relative soil water contents in the root zone as well as actual evapotranspiration rates, especially from September to April (wet season). This exacerbates a precise quantification of overall available water for individual years. However, best estimates of the preliminary study project annual overall available water resources to decline by $3.32 \mathrm{Mm}^{3}$ $(-66 \%)$ from $5.03 \mathrm{Mm}^{3}(1971-2000)$ to $1.71 \mathrm{Mm}^{3}(2041-$ 2070). Thereby soil water contents show a link with precipitation especially in the center of the watershed. Soil water storage fills during the wet period and dries out in the summertime (Fig. 3). Soils in the east seem to be more constant throughout the year. Their soil profile depth changes according to Korba aquifer thickness in individual model runs (ranging from $12.6 \mathrm{~m}$ to $70.2 \mathrm{~m}$ ). This results in an elevated water storage capacity for soils as well as water availability for plants in that region [3]. Other soils have a constant profile depth of $5 \mathrm{~m}$. The equalizing influence of Korba aquifer on soil water contents in the root zone may also be shown with the coefficient of variation $(\mathrm{COV}) . \mathrm{COV}$ is a measure of standard error that expresses the deviation of a variable from its mean value. COV calculates by $\mathrm{COV}=\sigma / \mu$, where $\sigma$ is the standard deviation and $\mu$ the mean characteristic of a respective key output of interest (KOI) over a certain time period (in this case: 30 years). In the eastern part of the watershed which is influenced of Korba aquifer, $\mathrm{COV}$ is more constant throughout all simulations. Other regions (especially the center) show more pronounced variances depending on rainfall characteristics (Fig. 4). Overall $\mathrm{COV}$ in Chiba basin dwindles from 0.2 to 0.19 . COV is elevated in the summertime. It is worth mentioning that mean values are small at that time so even a small rise results in a higher value of COV. 

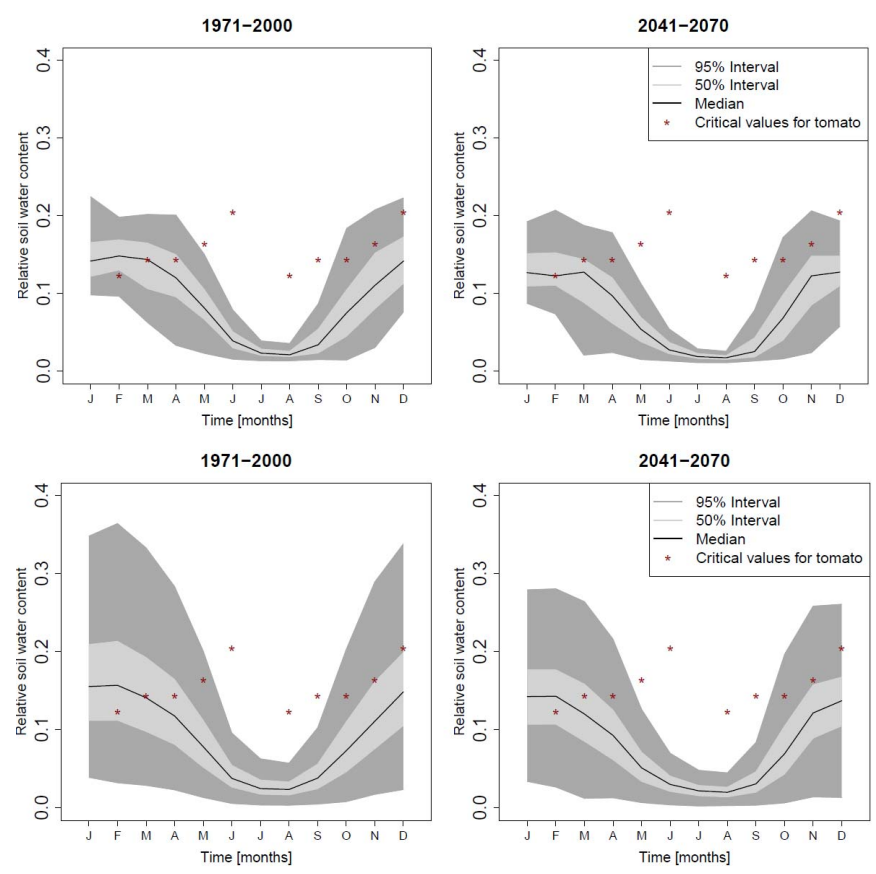

Figure 3: Simulated monthly mean values of relative soil water content in the root zone for 1971 - 2000 (left column) and 2041 - 2070 (right column). Dark red points indicate critical water contents for tomatoes. This kind of illustration may be used within CUS (upper row) and PUS (lower row) uncertainty studies (among other use cases) to estimate, at a later point of the project, the risk of not reaching critical values for specific crops in agriculture (in this case: tomatoes). In this case, 22 parameters were varied within PUS which are related to soil, land use, climate and groundwater settings of the model. Variations in those parameters lead to a wide variety of relative soil water content characteristics in individual model runs and thus a higher degree of uncertainty of this key output of interest (KOI) compared to CUS. Regardless, both studies feature a decline of relative soil water contents in the root zone between the reference and scenario period. The illustration is based on modified boxplots and originates from preliminary studies.
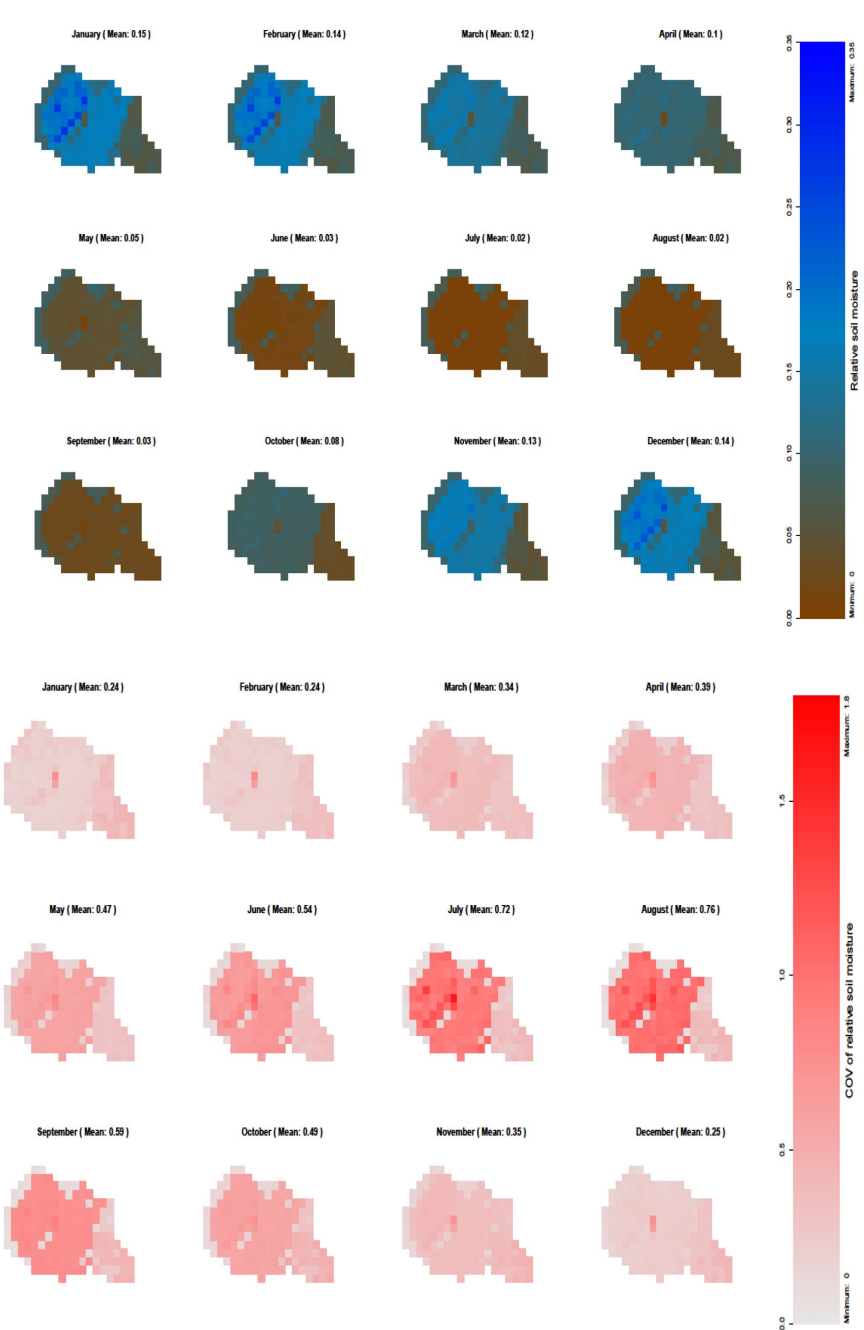

Figure 4: The upper window shows the spatial distribution of simulated monthly mean values of relative soil water content in the root zone in Chiba basin for the time period 2041 - 2070 (more intense blue colors indicate more water in the soil, whereas more intense brown colors indicate less water in the soil). The lower window shows the spatial distribution of the coefficient of variation (COV) for the same KOI in this time period. Areas with high values of COV indicate higher variations over time and hence a higher degree of uncertainty (more intense red color in illustration). Areas with low values of COV show more constant behaviour and thus less uncertainty (less intense red color in illustration). The illustrations once again are based on preliminary studies and give an example of how model results may be shown spatially distributed on a map.

\section{OUTLOOK}

This study gave an insight into setting up the "Water balance Simulation Model" WaSiM in Chiba basin, Tunisia. Furthermore, an outlook was presented of the upcoming modeling work which is intended after the WaSiM model has been finally set up in a robust and plausible way within the model harmonization strategy as well as the calibration/validation efforts. The modeling work will be described in a series of comprehensive publications in the future which will also be referenced on the official website of the CLIMB Project (www.climb-fp7.eu). In the end, those efforts will provide political decision makers with quantitative 
information on climate change impacts and associated uncertainties in all individual case study sites of CLIMB. This information creates a new knowledge base which can then be used for a better adapted water resource management in the future.

\section{ACKNOWLEDGMENT}

The CLIMB Project is kindly funded by the European Commission (grant number 244151).

\section{REFERENCES}

[1] R. Ludwig, R. Roson, C. Zografos and G. Kallis, "Towards an interdisciplinary research agenda on climate change, water and security in southern europe and neighbouring countries", Environmental Science and Policy, 14, 2011, pp.794-803.

[2] S. Benabdallah, F. Horriche, M. Anane and M. Bedir, "Climate Induced changes on the hydrology of mediterranean basins: Site characterization. Tunisian-Japan Symposium on regional development and water resources: A new vision for sustainable society", Tunis, Tunisia, 2010, pp. 65-67.

[3] J. Schulla, "Model description WaSiM (Water balance Simulation Model)", completely revised version 2012, last change: June 19, 2012.
[4] K. J. Beven, M. J. Kirkby, "A physically based variable contributing area model of catchment hydrology", Hydrological Sciences Bulletin, 24, 1979, pp. 43-68.

[5] L. A. Richards, "Capillary conduction of liquids through porous mediums", Physics, 1, 1931, pp. 318-333.

[6] J. Schulla, K. Jasper, "Model description WaSiM-ETH (water balance simulation model)", last updated: November 2007.

[7] S. L. Neitsch, J. G. Arnold, J.R. Kiniry and J. R. Williams, "Soil and water assessment tool", Theoretical documentation, Version 2009, Texas Water Resources Institute Technical Report No. 406, AgriLIFE Research\&Extension, Texas A\&M College of Agriculutre and Life Sciences, 2011.

[8] Camporese, M., C. Paniconi, M. Putti, and S. Orlandini, "Surfacesubsurface flow modeling with path-based runoff routing, boundary condition-based coupling, and assimilation of multisource observation data”, Water Resources Research, 46, W02512, doi:10.1029/2008WR007536, 2010.

[9] Danish Hydraulic Institute (DHI), "MIKE SHE user manual. volume 1: user guide", 2007.

[10] Danish Hydraulic Institute (DHI): "MIKE SHE user manual. volume 2: reference guide", 2007.

[11] European Commission, "Description of work (DOW) CLIMB - climate induced changes on the hydrology of mediterranean basins - reducing uncertainty and quantifying risk through an integrated monitoring and modeling system", Technical Report, European Commission, Community Research, Seventh Framework Programme, 2009. 